\title{
The Risk of Colorectal Cancer After Cholecystectomy or Appendectomy: A Population-based Cohort Study in Korea
}

\author{
Joonki Lee', Sunho Choe', Ji Won Park ${ }^{2,3}$, Seung-Yong Jeong ${ }^{2,3}$, Aesun Shin ${ }^{1,3}$ \\ ${ }^{1}$ Department of Preventive Medicine, Seoul National University College of Medicine, Seoul, Korea; ${ }^{2}$ Division of Colorectal Surgery, Department of \\ Surgery, Seoul National University College of Medicine, Seoul, Korea; ${ }^{3}$ Cancer Research Institute, Seoul National University, Seoul, Korea
}

Objectives: We investigated the association between cholecystectomy or appendectomy and the subsequent risk of colorectal cancer (CRC) in the Korean population.

Methods: A retrospective cohort study was conducted with the National Health Insurance Service-National Sample Cohort of Korea; this sample was followed up from January 1, 2002, until the date of CRC incidence, loss to follow-up, or December 31, 2015. The exposure status of cholecystectomy and appendectomy was treated as a time-varying covariate. The calculated risk of CRC was stratified by follow-up period, and the association between these surgical procedures and CRC was investigated by a Cox regression model applying appropriate lag periods.

Results: A total of 707663 individuals were identified for analysis. The study population was followed up for an average of 13.66 years, and 4324 CRC cases were identified. The hazard ratio (HR) of CRC was elevated in the first year after cholecystectomy (HR, 1.71; 95\% confidence interval [Cl], 1.01 to 2.89) and in the first year and 2-3 years after appendectomy (HR, 4.22; 95\% Cl, 2.87 to 6.20; $\mathrm{HR}, 2.34$; $95 \% \mathrm{Cl}, 1.36$ to 4.03 , respectively). The HRs of CRC after applying 1 year of lag after cholecystectomy and 3 years of lag after appendectomy were $0.80(95 \% \mathrm{Cl}, 0.57$ to 1.13$)$ and $0.77(95 \% \mathrm{Cl}, 0.51$ to 1.16$)$, respectively.

Conclusions: The risk of CRC increased in the first year after cholecystectomy and appendectomy, implying the possibility of bias. When appropriate lag periods after surgery were applied, no association was found between cholecystectomy or appendectomy and CRC.

Key words: Cholecystectomy, Appendectomy, Colorectal neoplasms, Cohort studies, Korea

Received: May 12, 2018 Accepted: October 9, 2018

Corresponding author: Aesun Shin, MD, PhD

Department of Preventive Medicine, Seoul National University College of Medicine, 103 Daehak-ro, Jongno-gu, Seoul 03080, Korea

E-mail: shinaesun@snu.ac.kr

This is an Open Access article distributed under the terms of the Creative Commons Attribution Non-Commercial License (http://creativecommons.org/licenses/by$\mathrm{nc} / 4.0 / /$ which permits unrestricted non-commercial use, distribution, and reproduction in any medium, provided the original work is properly cited.

\section{INTRODUCTION}

Colorectal cancer (CRC) is the third-leading cancer in the world and the third-most common cancer in both incidence and prevalence in Korea [1-3]. The age-standardized incidence rate (ASR) of CRC was 30.4 per 100000 in 2015; it rose by $6.0 \%$ annually from 1999 to 2010 , and has been decreasing by $4.9 \%$ annually since 2010 [3].

Several well-established risk factors are related to CRC [1]. For instance, age is closely associated with the risk of $C R C$, and diabetes mellitus (DM) and inflammatory bowel disease (IBD) 
are also known to increase the risk of CRC $[1,4,5]$. Environmental factors, including smoking, alcohol, and obesity, are associated with an increased risk of CRC [1].

Cholecystectomy and appendectomy are 2 of the most commonly performed surgical procedures in Korea [6], and are similar in terms of being performed under general anesthesia and involving the removal of an inflamed organ within the digestive tract. The association between these procedures and CRC has been of interest due to multiple potential biological mechanisms. Bile acid, which is synthesized in the liver and stored in the gallbladder, is known to be carcinogenic for CRC [7-9]. As a result of cholecystectomy, the exposure time of the intestinal mucosa to bile acid secretions increases, and cholecystectomy enhances negative feedback on bile acid synthesis in the liver [10], which could possibly alter the risk of CRC development. The appendix is thought to have an immune function in the bowel [11]. Because inflammation is considered to be a mechanism through which CRC develops, the risk of CRC may be changed after appendectomy.

Several studies have investigated the association between cholecystectomy and the risk of CRC [12-22]. Some of these studies have reported a modestly increased risk of CRC after cholecystectomy [12-16], but others reported no such association [17-21], and only 1 study reported a decreased risk [22]. The association between appendectomy and the risk of CRC has been studied, and an increased incidence of CRC after appendectomy was found [23-27]. Only 1 study reported no association between appendectomy and CRC [27]. These inconsistent results might be due to differences in dealing with bias. Protopathic bias, also called reverse causation, is a bias in which the exposure occurs as the result of the early manifestation of the targeted disease. To avoid this bias, an appropriate lag time is needed after exposure [28,29]. However, the lag times in previous studies varied, ranging from 0 to 6 years, and no obvious criteria were used to select the lag time. In this study, we investigated the association between cholecystectomy or appendectomy and the risk of subsequent CRC, considering this source of bias by applying an appropriate lag time in the analysis.

\section{METHODS}

\section{Data Source and Study Population}

Korea has a single medical insurance claim system that covers over $97 \%$ of the Korean population. This system provided a sample cohort, the National Health Insurance Service-National Sample Cohort (NHIS-NSC), for the purpose of research. It comprises approximately 1 million individuals, accounting for roughly $2 \%$ of randomly selected health insurance subscribers and Medical Aid recipients in the Korean population, and contains information on demographic factors, medical resource utilization, and regular medical check-up data from 2002 to 2015. The details of the cohort have been presented elsewhere [30].

We designed a retrospective cohort study using the NHISNSC, which comprises a total of 1108369 subjects from 2002 and 2015. To exclude subjects with a history of CRC, subjects who had any diagnostic code for CRC (C18-C20) from the 10th International Classification of Diseases (ICD-10) before January 2004 were excluded $(n=2082)$. In addition, subjects under 20 years of age at study entry were excluded $(n=298624)$. Finally, a total of 707663 subjects remained for analysis. During the study period, 11362 subjects underwent cholecystectomy, and 16094 subjects underwent appendectomy. The study population was followed until the end of the follow-up period or until the development of $\mathrm{CRC}$, whichever came first.

The study was exempted from review by the institutional review board of Seoul National University Hospital (H-1508-031694).

\section{Identification of Colorectal Cancer}

We identified CRC cases using ICD-10 codes. Subjects who simultaneously had a diagnostic code of CRC (C18-20) and the claim code for its treatment were identified as CRC cases. The treatments of CRC include surgery, chemotherapy, and radiation therapy, and are listed in Table S1. The incidence rate obtained using our definition was lower than that of the national cancer registry data, but the trends were similar (Figure S1). CRC cases were categorized into colon cancer (C18) and rectal cancer (C19-20), based on the ICD-10 code.

\section{Identification of Cholecystectomy and} Appendectomy

Cholecystectomy and appendectomy were identified by the insurance claim codes for these surgical procedures. Cholecystectomy covered cholecystectomy (Q7380) and radical cholecystectomy of gallbladder cancer (Q7410). Appendectomy covered appendectomy-simple (Q2861), appendectomy-perforated (Q2862), and removal of appendiceal abscess with periappendiceal abscess drainage (Q2863). The first date of 
the claim was defined as the surgery index date. Procedures performed after or simultaneously with the diagnosis of CRC were excluded from the study.

\section{Covariates}

We also extracted the following factors known to be associated with CRC: DM, IBD, smoking status, alcohol consumption, and high body mass index (BMI) $[1,4,31]$. Individuals who had DM were identified using the corresponding ICD-10 codes (E10-14) with a simultaneous prescription of hypoglycemic agents within the first 2 years after study entry. Individuals who had 2 claims per year of IBD based on the corresponding ICD-10 codes (K50, K51) in the first 2 years were defined as IBD patients. Lifestyle factors, such as smoking status, alcohol consumption, and BMI, were obtained from medical check-up data. These factors were identified based on the data available in the first 2 years of the study, and participants were classified by BMI into 2 groups ( $<25 \mathrm{~kg} / \mathrm{m}^{2}$ or not), based on the World Health Organization classification of overweight. However, medical check-up data were missing for over $70 \%$ of the subjects. Because reliable results cannot be obtained with more than half of the data missing, we considered these lifestyle factors not in the main analysis, but in the sensitivity analysis, in which the subjects were restricted to those who had available medical check-up data.

\section{Statistical Analysis}

The chi-square test and $t$-test were used to compare the baseline characteristics between patients who had ever undergone cholecystectomy during the study period and those who had not; the same procedures were also completed for appendectomy patients. We defined the status of cholecystectomy and appendectomy as a time-varying covariant, so that each individual was followed up as a non-exposure of cholecystectomy or appendectomy until the date of surgery.

We calculated the ASRs of CRC separately for the total study population, cholecystectomy patients, and appendectomy patients. ASRs were calculated using the mid-year Korean population in 2010 as the standard population and considering lag periods. The standardized incidence ratio was compared to the incidence in the study population, and $95 \%$ confidence intervals $(\mathrm{Cls})$ were calculated by the Poisson distribution.

The risk estimation for CRC was conducted separately for cholecystectomy and appendectomy. A time-dependent Cox proportional hazard regression model was used to calculate the hazard ratios (HRs) of cholecystectomy or appendectomy for the risk of CRC after adjusting for sex, DM, and IBD, and age was chosen as the time scale [32]. Initially, we evaluated the risk of CRC stratified by the follow-up time after cholecystectomy or appendectomy. Then, we applied an appropriate lag period after cholecystectomy or appendectomy in the Cox model and evaluated the risk of CRC after surgery. We also calculated the risk of CRC stratified by anatomical site based on the ICD-10 codes of colon cancer (C18) and recto-sigmoid cancer (C19-20). The proportional hazard assumption was checked by Schoenfeld residual plots. All statistical analyses were performed with SAS version 9.4 (SAS Institute Inc., Cary, NC, USA).

\section{Sensitivity Analysis}

Only 181933 subjects had medical check-ups in the first 2 years of the study. We performed a sensitivity analysis with these subjects to consider lifestyle factors. The baseline characteristics were compared in the same way as in the main analysis. In this analysis, HRs were computed using a time-dependent Cox proportional hazard regression model adjusted for sex, DM, IBD, smoking status, alcohol consumption, and $\mathrm{BMI}$. The CRC risk stratified by anatomical site was also computed in this analysis.

\section{RESULTS}

A total of 707633 subjects were included in the final analysis, with an average of 13.66 years of follow-up time, and 4324 subjects developed CRC during the study period. A comparison of the baseline characteristics between patients who underwent cholecystectomy or appendectomy and those who did not is shown in Table 1. Subjects who underwent cholecystectomy tended to be older and were more likely to have DM than those who did not. Those who underwent appendectomy tended to be younger and were more likely to be free of DM than those who did not.

The truncated ASR of CRC in the study population was 40.93 per 100000 person-years for adults aged 20 years and older (Table S2). The ASRs after cholecystectomy or appendectomy were 43.52 and 57.88 per 100000 person-years, respectively. The standardized incidence ratio of CRC after cholecystectomy was 0.97 ( $95 \% \mathrm{Cl}, 0.72$ to 1.29 ) compared to the total study population, and this was non-significant, even when lag periods were applied. The standardized incidence ratio of CRC after appendectomy was $1.43(95 \% \mathrm{Cl}, 1.11$ to 1.81$)$ which was 
Table 1. Characteristics of the study population, the National Health Insurance Service-National Sample Cohort, $2002-2015$

\begin{tabular}{|c|c|c|c|c|c|c|c|}
\hline \multirow{2}{*}{ Characteristics } & \multirow{2}{*}{ Total (n) } & \multicolumn{3}{|c|}{ Cholecystectomy } & \multicolumn{3}{|c|}{ Appendectomy } \\
\hline & & Without & With & $p$-value ${ }^{1}$ & Without & With & $p$-value ${ }^{1}$ \\
\hline Total & 707663 (100.0) & 696301 (98.4) & $11362(1.6)$ & & $691569(97.7)$ & 16094 (2.3) & \\
\hline Age $(y)^{2}$ & $41.70 \pm 14.7$ & $41.6 \pm 14.7$ & $47.8 \pm 14.6$ & $<0.001$ & $41.8 \pm 14.7$ & $39.1 \pm 14.4$ & $<0.001$ \\
\hline \multicolumn{8}{|l|}{ Sex } \\
\hline Male & $347411(49.1)$ & $341792(49.1)$ & 5619 (49.5) & 0.44 & 339458 (49.1) & 7953 (49.4) & 0.41 \\
\hline Female & 360252 (50.9) & 354509 (50.9) & $5743(50.5)$ & & $352111(50.9)$ & $8141(50.6)$ & \\
\hline \multicolumn{8}{|l|}{ Comorbidities } \\
\hline Diabetes mellitus & $22944(3.2)$ & $22211(3.2)$ & $733(6.5)$ & $<0.001$ & 22653 (3.3) & 291 (1.8) & $<0.001$ \\
\hline Inflammatory bowel disease & $361(0.1)$ & $354(0.1)$ & $7(0.1)$ & 0.61 & $347(0.1)$ & $14(0.1)$ & 0.04 \\
\hline
\end{tabular}

Values are presented as number (\%) or mean \pm standard deviation.

${ }^{1}$ The chi-square test for categorical values and the $t$-test for continuous values.

${ }^{2}$ Age at study entry.

Table 2. HRs for the incidence of colorectal cancer with cholecystectomy and appendectomy, based on the follow-up time

\begin{tabular}{|c|c|c|c|c|c|c|c|c|}
\hline & \multirow[b]{2}{*}{ Follow up (y) } & \multirow[b]{2}{*}{ Person-years } & \multicolumn{2}{|c|}{ Colorectal cancer } & \multicolumn{2}{|c|}{ Colon cancer (C18) ${ }^{1}$} & \multicolumn{2}{|c|}{ Rectal cancer (C19-C20) } \\
\hline & & & $\begin{array}{l}\text { No. of } \\
\text { events }\end{array}$ & $\begin{array}{c}\text { Adjusted HR } \\
\text { (95\% CI) }\end{array}$ & $\begin{array}{l}\text { No. of } \\
\text { events }\end{array}$ & $\begin{array}{c}\text { Adjusted HR } \\
(95 \% \mathrm{Cl})\end{array}$ & $\begin{array}{l}\text { No. of } \\
\text { events }\end{array}$ & $\begin{array}{c}\text { Adjusted HR } \\
(95 \% \mathrm{CI})\end{array}$ \\
\hline \multirow[t]{7}{*}{ Cholecystectomy } & Non-exposure & 9600974 & 4276 & 1.00 (reference) & 2539 & 1.00 (reference) & 1822 & 1.00 (reference) \\
\hline & $0-1$ & 10650 & 14 & $1.71(1.01,2.89)$ & 8 & $1.65(0.82,3.30)$ & 6 & $1.72(0.77,3.83)$ \\
\hline & $1-2$ & 9372 & 4 & $0.54(0.20,1.44)$ & 3 & $0.69(0.22,2.13)$ & 2 & $0.64(0.16,2.54)$ \\
\hline & $2-3$ & 8181 & 5 & $0.76(0.32,1.82)$ & 4 & $1.02(0.38,2.72)$ & 1 & $0.36(0.05,2.53)$ \\
\hline & $3-4$ & 7065 & 4 & $0.68(0.26,1.82)$ & 1 & $0.29(0.04,2.04)$ & 3 & $1.21(0.39,3.74)$ \\
\hline & $4-5$ & 5966 & 5 & $0.99(0.41,2.38)$ & 3 & $1.00(0.32,3.09)$ & 2 & $0.94(0.24,3.76)$ \\
\hline & $5+$ & 19808 & 16 & $0.88(0.54,1.44)$ & 7 & $0.64(0.31,1.35)$ & 9 & $1.18(0.61,2.26)$ \\
\hline \multirow[t]{7}{*}{ Appendectomy } & Non-exposure & 9550906 & 4255 & 1.00 (reference) & 2515 & 1.00 (reference) & 1824 & 1.00 (reference) \\
\hline & $0-1$ & 15534 & 26 & $4.22(2.87,6.20)$ & 21 & $5.74(3.73,8.81)$ & 5 & $1.89(0.79,4.54)$ \\
\hline & $1-2$ & 14474 & 7 & $1.19(0.57,2.50)$ & 6 & $1.72(0.77,3.82)$ & 1 & $0.40(0.06,2.81)$ \\
\hline & $2-3$ & 13332 & 13 & $2.34(1.36,4.03)$ & 8 & $2.42(1.21,4.84)$ & 6 & $2.53(1.14,5.64)$ \\
\hline & $3-4$ & 12157 & 5 & $0.97(0.40,2.33)$ & 2 & $0.65(0.16,2.61)$ & 4 & $1.81(0.68,4.83)$ \\
\hline & $4-5$ & 10933 & 5 & $1.06(0.44,2.54)$ & 4 & $1.42(0.53,3.79)$ & 1 & $0.49(0.07,3.51)$ \\
\hline & $5+$ & 44694 & 13 & $0.63(0.37,1.09)$ & 9 & $0.74(0.38,1.42)$ & 4 & $0.45(0.17,1.21)$ \\
\hline
\end{tabular}

Adjusted for sex, diabetes mellitus, and inflammatory bowel disease; Age was used as a time scale in the Cox proportional hazard model.

$\mathrm{HR}$, hazard ratio; $\mathrm{Cl}$, confidence interval.

${ }^{1}$ From the 10th International Classification of Diseases codes.

only significant with no lag period applied.

Stratified by the follow-up time since cholecystectomy, the risk of CRC was significantly elevated in the first year (HR, 1.71; $95 \% \mathrm{Cl}, 1.01$ to 2.89 ) (Table 2). However, it showed no association after 1 year post-cholecystectomy. The risk levels of colon cancer and rectal cancer were also elevated in the first year after cholecystectomy, although not to a statistically significant extent. Since the risk elevation in the first year after cholecystectomy may have been affected by bias, the HR when 1 year of lag was applied was $0.79(95 \% \mathrm{Cl}, 0.56$ to 1.10$)$ (Table 3). In the appendectomy cohort, the risk of CRC was elevated in the first year ( $\mathrm{HR}, 4.22 ; 95 \% \mathrm{Cl}, 2.87$ to 6.20$)$ and from 2 to 3 years ( $\mathrm{HR}, 2.34 ; 95 \% \mathrm{Cl}, 1.36$ to 4.03$)$ after surgery, and this risk elevation was prominent for colon cancer (Table 2). The risk from 1 to 2 years after appendectomy was elevated, but not significantly so (HR, 1.19; $95 \% \mathrm{Cl}, 0.57$ to 2.50$)$. Since this risk elevation may have been affected by bias, a lag period of 3 years was applied, and no association between appendectomy and $\mathrm{CRC}$ risk was found ( $\mathrm{HR}, 0.75 ; 95 \% \mathrm{Cl}, 0.50$ to 1.13$)$, even though the risk elevation was significant when no lag periods were applied (Table 3). Stratified by anatomical site, this tendency was more prominent for colon cancer than for rectal cancer 
Table 3. HRs for the incidence of colorectal cancer with cholecystectomy and appendectomy, with and without lag periods

\begin{tabular}{|c|c|c|c|c|}
\hline & \multirow{2}{*}{ Person-years } & \multicolumn{3}{|c|}{ Colorectal cancer } \\
\hline & & No. of events & Sex-adjusted HR $(95 \% \mathrm{CI})^{1}$ & Comorbidity-adjusted HR $(95 \% \mathrm{CI})^{2}$ \\
\hline \multicolumn{5}{|l|}{ Without lag periods } \\
\hline Appendectomy & 111125 & 69 & $1.44(1.13,1.82)$ & $1.44(1.14,1.83)$ \\
\hline \multicolumn{5}{|l|}{ With lag periods } \\
\hline
\end{tabular}

$\mathrm{HR}$, hazard ratio; $\mathrm{Cl}$, confidence interval.

${ }^{1}$ Age was used as the time scale in Cox proportional hazard model.

${ }^{2}$ Adjusted for sex, diabetes mellitus, and inflammatory bowel disease.

Table 4. HRs for the incidence of colon and rectal cancer with cholecystectomy and appendectomy, with and without lag periods

\begin{tabular}{|c|c|c|c|c|c|c|c|}
\hline & \multirow[b]{2}{*}{ Person-years } & \multicolumn{3}{|c|}{ Colon cancer (C18) ${ }^{1}$} & \multicolumn{3}{|c|}{ Rectal cancer (C19-C20) ${ }^{1}$} \\
\hline & & $\begin{array}{l}\text { No. of } \\
\text { events }\end{array}$ & $\begin{array}{l}\text { Sex-adjusted } \\
\text { HR }(95 \% \mathrm{CI})^{2}\end{array}$ & $\begin{array}{c}\text { Comorbidity-adjusted } \\
\text { HR }(95 \% \mathrm{CI})^{3}\end{array}$ & $\begin{array}{l}\text { No. of } \\
\text { events }\end{array}$ & $\begin{array}{l}\text { Sex-adjusted } \\
\text { HR }(95 \% \mathrm{CI})^{2}\end{array}$ & $\begin{array}{c}\text { Comorbidity-adjusted } \\
\text { HR }(95 \% \mathrm{CI})^{3}\end{array}$ \\
\hline Cholecystectomy & 61043 & 26 & $0.85(0.58,1.25)$ & $0.85(0.58,1.25)$ & 23 & $1.06(0.70,1.60)$ & $1.06(0.70,1.59)$ \\
\hline Appendectomy & 111125 & 50 & $1.75(1.32,2.32)$ & $1.76(1.33,2.32)$ & 21 & $1.02(0.66,1.57)$ & $1.03(0.67,1.58)$ \\
\hline \multicolumn{8}{|l|}{ With lag periods } \\
\hline Appendectomy (3 y of lag) & 67758 & 15 & $0.82(0.50,1.37)$ & $0.82(0.50,1.37)$ & 9 & $0.69(0.36,1.33)$ & $0.69(0.36,1.33)$ \\
\hline
\end{tabular}

$\mathrm{HR}$, hazard ratio; $\mathrm{Cl}$, confidence interval.

${ }^{1}$ From the 10th International Classification of Diseases codes.

${ }^{2}$ Age was used as the time scale in Cox proportional hazard model.

${ }^{3}$ Adjusted for sex, diabetes mellitus, and inflammatory bowel disease.

(Table 4). The risk could not be calculated in those who had both appendectomy and cholecystectomy because no CRC cases were identified in this sub-population after applying a lag period. The number of participants who underwent both cholecystectomy and appendectomy in the study period was 425. Among them, only 2 cases of CRC developed within 1 year of cholecystectomy or 3 years of appendectomy. For this reason, a risk estimation among patients who underwent both cholecystectomy and appendectomy could not be calculated. Because there was no pattern with time, we could confirm that the risk models fit the proportional hazard assumption for both cholecystectomy and appendectomy.

The characteristics of subjects who did and did not have available medical check-up data in the first 2 years are shown in Table S3. Subjects who had medical check-up data were older and were more likely to be male than those who did not. Additionally, they were more likely to have DM and IBD than those who did not have medical check-up data. A comparison of baseline characteristics among subjects with medical check-up data is shown in Table S4. The cholecystectomy pa- tients were younger than those who were not, and the appendectomy patients were older than those who were not. For lifestyle factors, the patients who underwent cholecystectomy tended to be non-smokers, never-drinkers, and to have a higher BMI, while the patients who underwent appendectomy tended to be non-smokers and current drinkers.

When the sample was restricted to subjects who had available medical check-up data, the results were similar to those of the main analysis (Table S5). The risk of CRC was elevated in the first year of cholecystectomy and appendectomy, and this elevation was prominent for colon cancer. No significant results were found when lag periods were applied in the sensitivity analysis (Table S6).

\section{DISCUSSION}

In this population-based cohort study, the risk of CRC was only elevated in the first year after cholecystectomy and the first 3 years after appendectomy. These results suggest the possibility of protopathic bias. When this bias was considered, 
associations between cholecystectomy or appendectomy and the risk of CRC were not shown. In the sensitivity analysis considering additional confounding factors, the risk was significantly elevated in the first year after cholecystectomy and appendectomy, as in the main analysis. However, the lag-applied analysis did not show any significant results, which might have been due to the small number of CRC cases.

Previous studies regarding the association between cholecystectomy and CRC have shown inconsistent results. Some previous studies have indicated a positive association between cholecystectomy and the risk of CRC, including 2 meta-analyses $[15,16]$. One meta-analysis covering 5 cohort studies and 33 case-control studies reported a relative risk (RR) of 1.22 (95\% $\mathrm{Cl}, 1.08$ to 1.38), but the pooled RR in cohort studies was 0.97 ( $95 \% \mathrm{Cl}, 0.82$ to 1.14). The results of the other meta-analysis covering 9 cohort studies showed a modestly increased risk ( $\mathrm{RR}, 1.22 ; 95 \% \mathrm{Cl}, 1.08$ to 1.38 ), and the result was only significant for colon cancer (RR, 1.30; $95 \% \mathrm{Cl}, 1.07$ to 1.58). Although a positive association was shown in other studies, it was significant only in short-term follow-up periods, as in our study $[12,14]$. No association was shown in other studies $[17,18,20$, 21], and another study conducted in US using the surveillance, epidemiology, and end results program Medicare data [22] showed a non-significant negative association between cholecystectomy and the risk of CRC (odds ratio, $0.97 ; 95 \% \mathrm{Cl}, 0.92$ to 1.02), which is similar to our results. The finding of an elevated risk in the first year after cholecystectomy can be explained by the similar clinical presentation of gallbladder disease and CRC. Furthermore, the misdiagnosis of early signs of CRC as gallbladder disease has been reported [33-35]. In our study, appendectomy increased the risk of CRC, especially in the first year, and this risk elevation was prominent for colon cancer. Although the risk elevation was not statistically significant in the second year of appendectomy, the risk seemed to be increased until 3 years after appendectomy. An elevated risk of CRC was not associated with appendectomy after 3 years. In addition, this risk elevation was significant only for colon cancer. This result might imply that appendicitis, the reason for appendectomy, could be an early sign of CRC, which has also been shown in other studies. The studies conducted by $\mathrm{Wu}$ and Colleagues $[25,26]$ reported that the risk tended to be elevated in shorter follow-up periods.

Our study had several strengths. First, this study used nationally representative data sources, and the sample comprised approximately 700000 individuals over 20 years old. Second, we dealt with time-dependent bias by conducting time-varying statistical analyses [36]. Third, the analysis focusing on the follow-up period provided evidence that protopathic bias was involved in the association. Thus, we found that considering a lag period is necessary when investigating associations between cholecystectomy or appendectomy and CRC.

However, our study also had limitations. Because we used claims data, the identification of CRC might not have been completely precise. However, a comparison of the incidence of CRC between our definition and that of the national cancer registry data showed a similar, but underestimated, trend. This underestimation could have led to undifferentiated misclassification bias. Although we analyzed over 700000 subjects, there were not enough newly developed CRC cases among cholecystectomy and appendectomy patients, because CRC is a rare disease, and there were not enough surgery cases, which could have been why our results did not show statistical significance. Cholecystectomies and appendectomies performed before 2002 could not be identified in this study. Because these surgical procedures do not need long-term followup, it was impossible to obtain patients' histories of these procedures through claims data. For this reason, some cases of surgery may have been present in the non-surgery cohort, rendering the results null. We could not consider other important possible confounding factors, such as colonic polyps or family history. We found that there was little change in the HRs when adjusting for history of DM, history of IBD, and lifestyle factors in the sensitivity analysis. In addition, information about colonoscopy could not be comprehensively collected because our data did not include data on colonoscopies performed for the purposes of screening or without any symptoms. Lastly, the follow-up time after surgery in our study might not have been sufficient for the development of CRC, which needs at least 5 to 10 years for carcinogenic changes [1]. In conclusion, the risk of CRC was not associated with cholecystectomy. However, the risk of CRC was elevated in the first year after cholecystectomy, likely due to gallbladder disease. The risk of CRC after appendectomy was significantly increased when no lag period was applied, but no association was found when applying 3 years of lag. The reason for this may be that appendicitis, which is the reason for appendectomy, could also be an early manifestation of CRC, whereas appendectomy is less likely to be a cause of CRC. To be protected from bias in analyses focusing on exposures such as surgery and $C R C$ risk, including lag periods after surgery is necessary. 


\section{ACKNOWLEDGEMENTS}

This study was supported by Seoul National University College of Medicine (Project no. 800-20170161).

\section{CONFLICT OF INTEREST}

The authors have no conflicts of interest associated with the material presented in this paper.

\section{SUPPLEMENTAL MATERIALS}

Supplementary Materials1-6: Table S1-S6 are available at https://www.jpmph.org/.

Supplementary Material 7: Figure S1 is available at https:// www.jpmph.org/.

\section{ORCID}

Joonki Lee $h$ ttp://orcid.org/0000-0002-5643-3062

Sunho Choe http://orcid.org/0000-0002-9460-8636

Ji Won Park http://orcid.org/0000-0003-0046-8175

Seung-Yong Jeong http://orcid.org/0000-0003-2726-4850

Aesun Shin http://orcid.org/0000-0002-6426-1969

\section{REFERENCES}

1. Haggar FA, Boushey RP. Colorectal cancer epidemiology: incidence, mortality, survival, and risk factors. Clin Colon Rectal Surg 2009;22(4):191-197.

2. Ferlay J, Soerjomataram I, Dikshit R, Eser S, Mathers C, Rebelo $\mathrm{M}$, et al. Cancer incidence and mortality worldwide: sources, methods and major patterns in GLOBOCAN 2012. Int J Cancer 2015;136(5):E359-E386.

3. Jung KW, Won YJ, Kong HJ, Lee ES; Community of PopulationBased Regional Cancer Registries. Cancer statistics in Korea: incidence, mortality, survival, and prevalence in 2015. Cancer Res Treat 2018;50(2):303-316.

4. Macrae FA. Colorectal cancer: epidemiology, risk factors, and protective factors; 2018 Jun 25 [cited 2018 Nov 1]. Available from: https://www.uptodate.com/contents/colorectal-cancer-epidemiology-risk-factors-and-protective-factors.

5. American Cancer Society. Colorectal cancer risk factors [cited 2018 Nov 1]. Available from: https://www.cancer.org/cancer/ colon-rectal-cancer/causes-risks-prevention/risk-factors. html\#references.

6. Hearing SD, Thomas LA, Heaton KW, Hunt L. Effect of cholecystectomy on bowel function: a prospective, controlled study. Gut 1999;45(6):889-894.

7. Schottenfeld D, Fraumeni JF Jr. Cancer epidemiology and prevention. 3rd ed. New York: Oxford University Press; 2006, p. 809-829.

8. Zuccato E, Venturi M, Di Leo G, Colombo L, Bertolo C, Doldi SB, et al. Role of bile acids and metabolic activity of colonic bacteria in increased risk of colon cancer after cholecystectomy. Dig Dis Sci 1993;38(3):514-519.

9. Nagengast FM, Grubben MJ, van Munster IP. Role of bile acids in colorectal carcinogenesis. Eur J Cancer 1995;31A(7-8):10671070.

10. Pomare EW, Heaton KW. The effect of cholecystectomy on bile salt metabolism. Gut 1973;14(10):753-762.

11. Randal Bollinger R, Barbas AS, Bush EL, Lin SS, Parker W. Biofilms in the large bowel suggest an apparent function of the human vermiform appendix. JTheor Biol 2007;249(4):826-831.

12. Schernhammer ES, Leitzmann MF, Michaud DS, Speizer FE, Giovannucci E, Colditz GA, et al. Cholecystectomy and the risk for developing colorectal cancer and distal colorectal adenomas. Br J Cancer 2003;88(1):79-83.

13. Shao T, Yang YX. Cholecystectomy and the risk of colorectal cancer. Am J Gastroenterol 2005;100(8):1813-1820.

14. Chen YK, Yeh JH, Lin CL, Peng CL, Sung FC, Hwang IM, et al. Cancer risk in patients with cholelithiasis and after cholecystectomy: a nationwide cohort study. J Gastroenterol 2014; 49(5):923-931.

15. Giovannucci E, Colditz GA, Stampfer MJ. A meta-analysis of cholecystectomy and risk of colorectal cancer. Gastroenterology 1993;105(1):130-141.

16. Zhang Y, Liu H, Li L, Ai M, Gong Z, He Y, et al. Cholecystectomy can increase the risk of colorectal cancer: a meta-analysis of 10 cohort studies. PLoS One 2017;12(8):e0181852.

17. Peng YC, Lin CL, Sung FC. The association between cholecystectomy and colorectal neoplasm in inflammatory bowel diseases: a population-based cohort study. PLoS One 2017;12(5): e0177745.

18. Zhao C, Ge Z, Wang Y, Qian J. Meta-analysis of observational studies on cholecystectomy and the risk of colorectal adenoma. Eur J Gastroenterol Hepatol 2012;24(4):375-381.

19. Chiong C, Cox MR, Eslick GD. Gallstone disease is associated with rectal cancer: a meta-analysis. Scand J Gastroenterol 2012;47(5):553-564. 
20. Shang J, Reece JC, Buchanan DD, Giles GG, Figueiredo JC, Casey $\mathrm{G}$, et al. Cholecystectomy and the risk of colorectal cancer by tumor mismatch repair deficiency status. Int J Colorectal Dis 2016;31(8):1451-1457.

21. Jørgensen T, Rafaelsen S. Gallstones and colorectal cancer-there is a relationship, but it is hardly due to cholecystectomy. Dis Colon Rectum 1992;35(1):24-28.

22. Nogueira L, Freedman ND, Engels EA, Warren JL, Castro F, Koshiol J. Gallstones, cholecystectomy, and risk of digestive system cancers. Am J Epidemiol 2014;179(6):731-739.

23. Ergul E, Gozetlik E. Does appendectomy increase the risk of colorectal adenocarcinoma? Open Med 2009;4(3):315-319.

24. Lai HW, Loong CC, Tai LC, Wu CW, Lui WY. Incidence and odds ratio of appendicitis as first manifestation of colon cancer: a retrospective analysis of 1873 patients. J Gastroenterol Hepatol 2006;21(11):1693-1696.

25. Wu SC, Chen WT, Muo CH, Ke TW, Fang CW, Sung FC. Association between appendectomy and subsequent colorectal cancer development: an Asian population study. PLoS One 2015; 10(2):e0118411.

26. Wu SC, Chen WT, Muo CH, Sung FC. Appendicitis as an early manifestation of subsequent malignancy: an asian population study. PLoS One 2015;10(4):e0122725.

27. Song H, Abnet CC, Andrén-Sandberg $\AA$, Chaturvedi AK, Ye W. Risk of gastrointestinal cancers among patients with appendectomy: a large-scale Swedish register-based cohort study during 1970-2009. PLoS One 2016;11(3):e0151262.

28. Tamim H, Monfared AA, LeLorier J. Application of lag-time into exposure definitions to control for protopathic bias. Pharmacoepidemiol Drug Saf 2007;16(3):250-258.

29. Armenian HK. Incubation periods of cancer: old and new. J Chronic Dis 1987;40 Suppl 2:9S-15S.

30. Lee J, Lee JS, Park SH, Shin SA, Kim K. Cohort profile: the National Health Insurance Service-National Sample Cohort (NHIS-NSC), South Korea. Int J Epidemiol 2017;46(2):e15.

31. Johnson CM, Wei C, Ensor JE, Smolenski DJ, Amos Cl, Levin B, et al. Meta-analyses of colorectal cancer risk factors. Cancer Causes Control 2013;24(6):1207-1222.

32. Thiébaut AC, Bénichou J. Choice of time-scale in Cox's model analysis of epidemiologic cohort data: a simulation study. Stat Med 2004;23(24):3803-3820.

33. Wysocki A, Lejman W, Bobrzynski A. Abdominal malignancies missed during laparoscopic cholecystectomy. Surg Endosc 2001;15(9):959-961.

34. Goldacre MJ, Wotton CJ, Abisgold J, Yeates DG, Collins J. Association between cholecystectomy and intestinal cancer: a national record linkage study. Ann Surg 2012;256(6):1068-1072.

35. Gál I, Szívós J, Jaberansari MT, Szabó Z. Laparoscopic cholecystectomy. Risk of missed pathology of other organs. Surg Endosc 1998;12(6):825-827.

36. Wolkewitz M, Allignol A, Harbarth S, de Angelis G, Schumacher M, Beyersmann J. Time-dependent study entries and exposures in cohort studies can easily be sources of different and avoidable types of bias. J Clin Epidemiol 2012;65(11):11711180. 